\title{
ENSAIO
}

\section{BANALIDADE DO MAL, ANESTESIA CULTURAL, COMUNIDADES SEXUALIZADAS E TRANSFEMINISMOS: ALGUMAS REFLEXÕES ${ }^{1}$}

Rafael da Silva Noleto ${ }^{2}$

Resumo: Articulando os conceitos de banalidade do mal (Hannah Arendt) e Anestesia Cultural (Allen Feldman), busco apresentar casos recentes envolvendo mortes de pessoas trans, seja por violência transfóbica (Dandara dos Santos Fortaleza, CE - e Patrícia Ferraz - Belém, PA) ou por adoecimento (Raíssa Gorbatchof - Belém, PA). A intenção é argumentar acerca da importância dos transfeminismos no combate à vulnerabilidade à qual a população travesti e transexual está sujeita cotidianamente. Pretendo refletir sobre como as formas de extermínio desses sujeitos buscam reconstruir as nações como comunidades sexualizadas, pautadas na hegemonia da heterossexualidade e cisgeneridade.

Palavras-chave: Transexualidade; Transfeminismos; Violência.

\section{Introdução}

Nos últimos anos, temos tido acesso a informações alarmantes que nos falam a respeito das inúmeras mortes de travestis, transexuais e pessoas que vivenciam diversas identidades transgênero. Recentemente, um dos assassinatos mais brutais de que se teve notícia vitimou a transexual Dandara dos Santos, espancada até a morte na cidade de Fortaleza, Ceará. Seus últimos e degradantes instantes de vida foram registrados em vídeo como um último ato de violência que perpetuou, em imagens, sua condição inevitável de subalternidade. As imagens da crueldade praticada contra a existência de Dandara foram veiculadas nas redes sociais e em diversos aplicativos de chat que trataram de propagar o horror de sua morte. O que nos dizem essas

\footnotetext{
${ }^{1}$ Texto extraído de palestra proferida pelo autor durante o "I Simpósio Feminista da UFT", realizado em 22 de março de 2017.

2 Professor Adjunto na Universidade Federal do Tocantins. Doutor em Antropologia Social (PPGAS/USP). Atua como docente no Programa de Pós-Graduação em Cultura e Território (PPGCult/UFT) e no curso de Licenciatura em Ciências Sociais. Coordena o Grupo de Pesquisa em Gênero, Etnicidade e Sexualidade em Contextos Interétnicos (GESCI/UFT).
} 
imagens que espetacularizam a morte de uma pessoa trans na sociedade brasileira contemporânea? Qual o nível de resistência de nossas sensibilidades ao suportarmos ver o aniquilamento de um corpo, de uma existência, de uma identidade e de uma subjetividade que subverte a hegemonia da heterossexualidade e da cisgeneridade? Se, por um lado, o assassinato de Dandara dos Santos aparenta falsamente ter sido "único" (ou uma "exceção") devido à sua eternização em imagens, por outro lado, nós sabemos, para nossa infelicidade, que esta morte brutal é apenas uma dentre muitas. O relatório divulgado pela Anistia Internacional não deixa dúvidas: o Brasil é o país que mais mata pessoas LBGTI no mundo ${ }^{3}$.

No sentido de esboçar alguma contribuição que nos permita refletir sobre este campo, busco, neste ensaio, conectar a morte de Dandara dos Santos ao falecimento de Patrícia Ferraz e Raíssa Gorbatchof, entendendo que a perda dessas vidas (travestis e transexuais) não pode ser compreendida de modo isolado, mas numa perspectiva de que essas mortes integram um sistema maior, que visa eliminar vidas e corpos indesejáveis para construir uma comunidade nacional sexualizada, pautada na hegemonia da heterossexualidade e da cisgeneridade. Nesse projeto de heterossexualizar e cisgenerizar a nação, há o pressuposto cruel do extermínio físico e simbólico das populações que desafiam os padrões hegemônicos de gênero e sexualidade. E é a partir desse dispositivo de matar ou de deixar morrer, que nossas sensibilidades vão, gradativamente, sendo anestesiadas, tornando-se relativamente indiferentes ao mal banalizado de modo institucional.

Dandara, Patrícia e Raíssa morreram de formas diferentes, mas não menos cruéis e brutais. Suas existências nos fazem pensar acerca da necessidade urgente de somarmos vozes ao coro dos transfeminismos, entendendo e respeitando o protagonismo dos sujeitos políticos (as pessoas trans) que vivem em condições de subalternidade e que podem e devem falar por si. No entanto, na atual conjuntura de retrocessos políticos que vive o Brasil, penso que nunca é demais adicionarmos outras vozes às reivindicações relativas ao acesso aos direitos civis, políticos e sociais por parte da população LGBTI. E, na condição de homem cisgênero, "branco", classe média e homossexual, antropólogo que pesquisa a articulação de questões de gênero, raça e sexualidade, venho tentar esboçar alguma contribuição sobre um tema tão atual, complexo e contemporâneo que são os transfeminismos. Em minhas reflexões

\footnotetext{
${ }^{3}$ Ver notícia disponível em: https://anistia.org.br/noticias/brasil-lidera-numero-de-assassinatos-dediversos-grupos-de-pessoas-em-2017-aponta-anistia-internacional-em-novo-relatorio/ [Acesso em 02 de junho 2018]
} 
sobre essas temáticas, busco pensar que as questões de gênero e sexualidade estão articuladas a outras problematizações correlatas tais como as relações raciais, os conflitos entre classes sociais, as reivindicações de caráter étnico e, finalmente, as divisões geracionais que nos fazem produzir lugares sociais específicos para diferentes estratificações etárias nas sociedades nas quais vivemos. Com base nesses pressupostos, compartilho adiante alguns apontamentos acerca dos transfeminismos e suas implicações para a constituição de comunidades sexualizadas.

\section{Dandara dos Santos}

Dito isto, quero adentrar o tema que me propus debater aqui. Ressalto que minhas contribuições serão de caráter menos teórico e mais etnográfico. Para começar, evoco aqui um dos mais recentes casos de transfobia de que tivemos notícia: o assassinato de Dandara dos Santos, transexual de Fortaleza - CE. As cenas de horror foram amplamente divulgadas em diversos veículos disponíveis na internet e em grupos de chat no WhatsApp. O que nos dizem aquelas imagens? Mesmo sem ter tido a curiosidade perturbadora de assistir àquelas cenas de violência, perpetuando-as ao lhes dar audiência, penso que essas imagens dizem a respeito daquilo que, com as devidas diferenças e proporções, Hannah Arendt (1999 [1963]) chamou como banalidade do mal.

Para a autora, o mal não corresponde em si a uma característica ontológica de certos sujeitos, pois o mal é produzido e cultivado em sistemas sociais e políticos nos quais há instituições para lhes dar suporte ideológico. A vida burocratizada que nos é colocada pela relação estabelecida com o Estado e os processos alienantes que nos levam a uma incapacidade de reflexão crítica e política acerca dos nossos próprios atos, acabam por nos transformar em potenciais (re)produtores da banalidade do mal. Assim, a violência torna-se trivial porque é institucionalizada e, por isso, rotineira ou, nas palavras de Hannah Arendt, banalizada. A banalidade do mal é consequência e não causa, é produzida sistematicamente porque, através da burocracia e de medidas políticas específicas, cria grandes divisores, estabelecendo vidas que importam e vidas que não importam. E aqui o conceito de instituições ao qual me refiro possui uma amplitude semântica mais alargada. Refiro-me não apenas às instituições em sentido formal como Instituições do Estado ou Instituições Religiosas. Considero como instituições também os valores morais arraigados no senso comum, muitos deles advindos dos complexos dispositivos políticos 
engendrados pelo Estado e por certos grupos religiosos (também numerosos e imbricados na composição do Estado) para deslegitimar vidas.

Ainda na esteira das reflexões de Hannah Arendt e o seu conceito de banalidade do mal, tendo a concordar com as reflexões de Allen Feldman e sua noção de anestesia cultural. Feldman - baseado em Theodor Adorno - elaborou a noção de "anestesia cultural" ao analisar que, durante e após o Holocausto, criou-se um contexto de massificação e objetificação, em termos quantitativos e qualitativos, da dor infligida sobre os corpos de certas alteridades indesejáveis. Assim, a partir desse processo de objetificação da dor e dos “outros" - possibilitada e mediada pelos grandes veículos de comunicação - há um crescimento da capacidade social de imputar a dor sobre o "outro" e de tornar a dor do "outro" como inadmissível para o discurso público e para a cultura "dominante" (FELDMAN, 1994, p. 406). O autor considera que os meios de comunicação, (re)produtores da massificação dos acontecimentos, são a base sobre a qual se erige certa cultura de percepção sensorial anestésica com relação a alteridades que não importam. Essa percepção sensorial seletiva está pautada em representações imagéticas específicas tanto com relação aos agentes quanto aos objetos da violência. Feldman (1994, p. 407) problematiza os mecanismos por meio dos quais a mídia produz, discursivamente, uma despersonalização dos corpos ao veiculá-los como artigos de massa, ou seja, um conjunto disperso de corpos feridos, famintos, mortos, doentes e sem-teto em relação aos quais o sentimento de dor é banalizado e deslegitimado. O conceito de "anestesia cultural" de Allen Feldman evidencia o quanto somos conduzidos/as a um processo de especialização da experiência sensorial, que nos faz sentir por uns, mas não por “outros".

Sendo assim, as imagens de Dandara dos Santos sendo assassinada tornam evidente o fato de que vivemos em tempos de anestesia cultural, isto é, uma incapacidade moral de sentir a dor do outro que não nos é inteligível. Vivemos em tempos nos quais há uma desfaçatez na manifestação de preconceitos e opiniões assassinas, que definem os corpos que importam, para usar uma expressão de Judith Butler. Para além da crueldade, da banalidade do mal ou da anestesia cultural, as imagens da morte de Dandara dos Santos nos falam da pertinência dos transfeminismos. De acordo com Viviane Vergueiro (2015) e Amara Moira Rodovalho (2017), é preciso desnaturalizar um CIStema (escrito com C) que patologiza a transexualidade ou transgeneridade como um desvio, como loucura, 
como doença. E, nesse sentido, considero ser necessário problematizar a categoria cis.

Anne Finn Enke (2012) historiciza o uso desse termo cis destacando seu surgimento como um neologismo, criado no âmbito da biologia por Dana Leland Defosse, e assinalando o trânsito polissêmico dessa categoria entre os contextos da academia e dos movimentos sociais LGBT (lésbicas, gays, bissexuais, travestis e transexuais).

Por um lado, o termo "cisgênero" serve para evidenciar uma categoria de análise que, de certo modo, desnaturaliza a condição hegemônica de convergência entre o sexo biologicamente atribuído e a identidade de gênero socialmente vivenciada. Dessa maneira, o uso dessa categoria causa um efeito de estranhamento, pois os sujeitos considerados "cisgênero" não estão habituados a pensarem sobre si próprios a partir de uma categoria de análise que os retire do patamar da norma. Esse efeito de estranhamento acaba por demonstrar que a cisgeneridade é apenas uma das possibilidades de experiência social com a identidade de gênero em interface com o sexo biológico.

Por outro lado, Enke chama a atenção para a armadilha contida no uso dessa categoria, tendo em vista que "cisgênero" é também um termo que causa o efeito oposto de naturalizar, essencializar e estabilizar as categorias "mulher" e "homem". Em sua crítica, Enke assinala que "justamente quando a teoria queer e trans nos lembra que sexo e gênero são construídos e não têm estabilidade a priori ("não se nasce uma mulher"), o termo cisgênero chega para afirmar não só que é possível para alguém permanecer "uma mulher", mas também que, afinal, esse alguém "nasce mulher" (ENKE, 2012, p. 63 - Tradução livre do autor). Devo ressaltar que utilizo o termo "cisgênero" como forma de interpelar a suposta naturalidade de uma categoria de sujeitos que, em geral, se percebe como auto evidente e que não é desnaturalizada em sua condição de norma.

\section{Raíssa Gorbatchof e Patrícia Ferraz}

Após essa discussão inicial, gostaria, agora, de falar a partir dos resultados de minha pesquisa de doutorado (NOLETO, 2014; 2016a; 2016b; 2017) sobre a participação de homossexuais e pessoas "trans" na realização dos concursos de quadrilha promovidos pelo Governo do Estado do Pará e pela Prefeitura Municipal de Belém (PA) a fim de evidenciar algumas questões que tangenciam os 
transfeminismos dos quais hoje falamos, destacando o protagonismo travesti da militante Raíssa Gorbatchof.

Em Belém, há um consenso muito disseminado de que "São João é coisa de viado" ou, simplesmente, de que "não existe festa junina sem as gays". Essas são frases que, com muita frequência, são proferidas por pessoas diretamente vinculadas ao universo profissional da cultura popular na cidade. Embora os folguedos juninos sejam reconhecidamente voltados para todos e quaisquer sujeitos que deles queiram participar, há uma presença inegável de homens homossexuais, mulheres transexuais, travestis e pessoas transgênero nesse contexto festivo. Assim, os festejos juninos se configuram como importantes acontecimentos que atraem e inserem a participação destes sujeitos no campo da cultura popular de Belém. Não há aqui a intenção de negar que haja uma grande adesão de pessoas heterossexuais e cisgênero às festas juninas da cidade, mas sim o intuito de direcionar um olhar mais cuidadoso para os significados da atuação expressiva de gays e pessoas "trans" nesse âmbito.

Atualmente, a quadra junina em Belém consiste na realização de dezenas de concursos festivos nos quais as quadrilhas, grupos coreográficos juninos, disputam títulos de reconhecimento relativos à qualidade de suas apresentações. Inseridos no âmbito dos concursos de quadrilha de modo paralelo e concomitante, há os concursos juninos de miss, nos quais algumas brincantes de destaque disputam os títulos de Miss Caipira, Miss Mulata (ou Morena Cheirosa), Miss Simpatia e Miss Gay (ou Mix). Na linguagem corrente, os quadrilheiros operam com um grande divisor generificado para designar esses certames de modo mais amplo como concursos de miss mulher (referindo-se às categorias de disputa para mulheres cisgênero) e concursos de miss gay/mix (aludindo à categoria única de disputa destinada aos homossexuais e pessoas "trans").

Os concursos de quadrilha caracterizam-se pela disputa entre grupos (compostos por cerca de 22 a 24 pares de dançarinos) que dançam coreografias representativas de certos ideais de ruralidade e de heterossexualidade. Cada quadrilha deve apresentar uma coreografia com cerca de 20 minutos de duração, um limite de tempo que varia de acordo com os diferentes regulamentos que orientam os concursos. O certame consiste, portanto, em escolher qual a melhor quadrilha que se apresentou para o público presente e para um corpo de jurados especializado. Apesar de ter intensa participação homossexual, travesti, transexual e transgênero (sujeitos que podem ser integrados às quadrilhas ocupando as funções "femininas" na coreografia), os concursos de quadrilha não são voltados especificamente para este 
público, admitindo, portanto, homens e mulheres heterossexuais e cisgênero como dançarinos.

Com relação às misses, como são popularmente conhecidas, pode-se afirmar que são dançarinas que possuem status diferenciado dentro de uma quadrilha junina, pois são as principais representantes destes grupos coreográficos e, por este motivo, disputam títulos de reconhecimento que estão diretamente relacionados à avaliação de sua beleza, seu traje e suas habilidades em dança. Antes de cada quadrilha se apresentar para um júri especializado, as "misses" que a representam dançam e investem na conquista de um título correspondente à sua categoria. Entretanto, a Miss Gay (ou Mix) é a única que não dança caracterizada como tal junto com sua respectiva quadrilha, mas possui um concurso específico para sua categoria realizado em data diferenciada. Ao contrário dos concursos de quadrilha, que julgam uma competência coreográfica coletiva, a ênfase dos concursos de miss recai sobre a individualidade das candidatas, cabendo a análise de seus atributos performáticos individuais.

Adentro diretamente o ponto de discussão onde quero chegar, é necessário dizer que, apesar de já promover concursos de quadrilha há muitas décadas, a Prefeitura de Belém só veio realizar o concurso "Miss Caipira Gay" a partir do ano de 2001, quando houve uma polêmica, amplamente divulgada na imprensa local, envolvendo a travesti Raíssa Gorbatchof. A querela foi documentada em reportagem de Suely Nascimento (2001) e dizia respeito a uma denúncia relativa à participação da travesti Raíssa Gorbatchof dançando como dama em uma quadrilha junina. $\mathrm{Na}$ reportagem, Raíssa advogava em favor de que homossexuais e travestis pudessem desempenhar, coreograficamente, os papeis femininos nas apresentações das festas de São João em Belém. Quando tive contato pessoal com Raíssa Gorbatchof, ela fez questão de ressaltar que homossexuais e travestis sempre tiveram, historicamente, uma grande participação nos bastidores das festas juninas, alegando, dessa maneira, que a proibição da participação destes sujeitos nas quadrilhas era injusta. Em 2001, Raíssa era militante do então Movimento Homossexual de Belém (MHB), onde buscou parcerias de caráter mais institucional para fazer pressão à Prefeitura Municipal de Belém no sentido de permitir nos regulamentos de certames juninos a participação de homossexuais e pessoas "trans" nos papéis coreográficos mais condizentes com suas respectivas identidades sexuais e de gênero. Vitória de Raíssa e do MHB: após tensas negociações, a comissão organizadora dos concursos de quadrilha promovidos pela prefeitura de Belém resolveu permitir a participação de 
homossexuais e pessoas "trans" dançando como damas nos grupos, sem a penalização de desclassificá-los dos certames. Nesse mesmo período, a FUMBEL (Fundação Cultural do Município de Belém) instituiu o concurso "Miss Caipira Gay”, que visava dar mais visibilidade à diversidade sexual e de gênero que é constitutiva do movimento junino existente em Belém.

Esse debate foi muito representativo da possibilidade de diálogo mais progressista que o movimento homossexual da época teve com o poder executivo exercido pelo prefeito Edmilson Rodrigues (que era filiado ao PT). Sendo assim, os regulamentos desses concursos passaram a utilizar a palavra par para designar as duplas de brincantes que integrarão as quadrilhas, sem fazer restrições relativas nem ao gênero nem à sexualidade dos participantes. $\mathrm{O}$ atual entendimento veiculado pelo Estado é o de que as quadrilhas devem ser formadas por pares e não por casais. Ao substituir a palavra casal - anteriormente utilizada para designar as duplas de brincantes compostas por um homem e uma mulher - pelo termo pares, criou-se a possibilidade de regulamentação definitiva da participação de homossexuais e pessoas "trans" no conjunto de brincantes das quadrilhas. Se, por um lado, a mudança nos regulamentos representou um avanço para a integração da comunidade LGBT no contexto da cultura popular de Belém, por outro lado, a forma como essa integração foi feita subentende uma violência simbólica ao negar o status de casal às formações performáticas de duplas compostas por sujeitos políticos que não se encaixam nem nas divisões binárias de gênero nem no critério de serem protagonistas no campo da ideologia da heterossexualidade compulsória. É importante ressaltar que esse não é um entendimento apenas local e regional, restrito a Belém e ao Pará. Pelo contrário, os regulamentos mais recentes dos concursos nacionais promovidos pela CONFEBRAQ (Confederação Brasileira de Entidades de Quadrilhas Juninas) também utilizam a nomenclatura pares a fim de designar as duplas de brincantes que performatizam identidades "masculinas" e "femininas" evitando, dessa maneira, o termo casal.

$\mathrm{O}$ entendimento demonstrado pelas/os gestoras/es culturais acerca desta temática é o de que, apesar de os regulamentos permitirem, por exemplo, que homossexuais e pessoas "trans" desempenhem o papel de damas nos concursos de quadrilha, a descaracterização da díade masculino/feminino enfatizada pelas coreografias e trajes vestidos pelos pares é vetada. Sugiro, portanto, que os certames juninos sustentam uma concepção normativa baseada na pressuposição da heterossexualidade e de um ideal de cisgeneridade dos sujeitos. Chamo esse processo 
de heterossexualidade e cisgeneridade coreográfica para designar uma narrativa dançada, nem sempre interpretada por sujeitos heterossexuais e cisgêneros, que é elaborada para criar efeitos performativos de heterossexualidade e cisgeneridade. Assim, quando os regulamentos juninos admitem a adoção do termo pares em detrimento da expressão casais, produz-se um efeito performático de heterossexualidade e cisgeneridade que não é necessariamente representativo das verdadeiras identidades sexuais e de gênero dos brincantes em suas respectivas quadrilhas.

Deve-se ressaltar que em Belém e em grande parte do Pará as quadrilhas não apresentam, compulsoriamente, uma narrativa pautada na celebração de um casamento, como é usual em muitos outros estados brasileiros. O casamento é subentendido, omitido, "ignorado" ou, em algumas raras coreografias, celebrado. Sugiro que a ausência ou a opacidade do casamento no plano performático de muitas quadrilhas de Belém acompanha a dinâmica social contemporânea da fluidez dos afetos, das experimentações sexuais, da menor estabilidade das relações e do relaxamento em torno da obrigatoriedade de um matrimônio vitalício. Se parece renovador o protagonismo de alguns desses sujeitos da feminilidade no contexto junino encenando relações afetivo-sexuais que desafiam a heterossexualidade e a divisão binária dos gêneros, proponho que isso se deve à própria emergência contemporânea de novas identidades sexuais que demandam a legitimação de conjugalidades que extrapolam a heterossexualidade na esfera social. O grande obstáculo a ser transposto após um processo de legitimação de conjugalidades não heterossexuais é o fato de que "a esfera da aliança íntima legítima é estabelecida graças à produção e à intensificação de zonas de ilegitimidade” (BUTLER, 2003, p. 226). Ou seja, o reconhecimento da legitimidade de certas ligações de parentesco por aliança entre pessoas não heterossexuais cria, por oposição, algumas zonas ilegítimas do gênero, da sexualidade e dos vínculos conjugais. Raíssa Gorbatchof, a travesti militante que inseriu definitivamente a comunidade LGBT nos certames juninos do Pará, morreu em 2013, vítima de complicações causadas pelo vírus HIV. Raíssa deixou marcas profundas no São João de Belém.

Para encerrar os comentários que tenho a fazer acerca da diversidade sexual e de gênero no São João de Belém, quero contar a história de Patrícia Ferraz. Em 2014, quando a conheci, Patrícia tinha 26 anos, intitulava-se mulher transexual (às vezes referindo-se a si como gay ou mesmo travesti), autodeclarada como "morena cor de jambo". Nascida em Marapanim, município do interior do Pará localizado no 
litoral atlântico do Estado, Patrícia residia em Belém e já acumulava uma trajetória de 10 anos como brincante no São João. Patrícia desfrutava do privilégio de ser considerada uma transexual bela, uma "morena bonita", "muito gata", "linda" ou simplesmente "gostosa", como ouvi de alguns homens quando se referiam a ela. A atestação de sua beleza vinha acompanhada do reconhecimento de sua “feminilidade". E foram estas características físicas, aliadas a uma performance de gênero bem "feminina", que renderam à Patrícia o posto de dama na Fuzuê Junino, quadrilha do bairro da Pedreira. Conheci Patrícia dançando nos certames de junho e confesso que sua condição transexual me passou despercebida. Achei que se tratava de uma mulher cisgênero e notei que não fui o único que pensava dessa maneira quando estabelecia os primeiros contatos visuais com Patrícia. Sua "feminilidade" era incontestável e estava plenamente diluída no conjunto de damas do qual era integrante. Patrícia me contou que "a Fuzuê Junino é uma quadrilha muito rígida, não aceita qualquer trans". Em suas palavras, para ser dama nessa quadrilha "a trans tem que ser mulher mesmo, bem feminina. Os jurados têm que bater o olho e jurar que ela é mulher”. Patrícia conseguiu vencer essa barreira, dançou nos certames representando a Fuzuê Junino e, após o ciclo festivo de junho, continuamos mantendo contato pelas redes sociais ou mesmo por telefone.

Naquele ano, Patrícia havia tomado uma decisão: mudaria de Belém para São Paulo em busca da efetivação completa de seu processo transexualizador. A decisão de mudar para São Paulo estreitou os laços que tínhamos. Passei a conversar mais assiduamente com Patrícia, pois ela tinha conhecimento de que eu morava em São Paulo devido ao vínculo com o curso de doutorado em Antropologia Social na USP (Universidade de São Paulo). Nossas conversas giravam em torno da vida noturna da cidade, especialmente no que diz respeito ao mercado da prostituição, ramo profissional do qual Patrícia era integrante.

Durante o trabalho de campo, foram registradas, através das fotografias de Marcus Negrão (meu companheiro), muitas cenas etnográficas dos concursos juninos. Diversas imagens de Patrícia estavam nesse acervo. O acúmulo deste material estimulou que Marcus e eu escolhêssemos algumas imagens com o objetivo de pleitear a publicação de um ensaio fotográfico em alguma revista acadêmica da área de Antropologia. Contei a Patrícia que tínhamos escolhido uma fotografia sua e prometi avisar caso o ensaio fosse realmente publicado. Entre o tempo de análise do ensaio fotográfico pela comissão editorial e sua efetiva publicação, Patrícia Ferraz mudou-se para Piracicaba, município do interior de São Paulo, no final do ano de 
2014. Ao contrário do que conversávamos por telefone, sua mudança para a capital não foi possível, pois tinha amigas mais confiáveis que já trabalhavam no interior e poderiam facilitar sua inserção no mercado do sexo. Logo quando se mudou para Piracicaba, Patrícia entrou em contato comigo, convidou-me para visitá-la, contoume que estava feliz e que iria realizar o sonho de se transformar em mulher.

Na tarde do dia 24 de março de 2015, soube da notícia da publicação do ensaio fotográfico no qual havia uma imagem de Patrícia (NOLETO e NEGRÃO, 2015). Imediatamente, divulguei as fotos em minha página pessoal no Facebook e logo Patrícia tomou conhecimento da novidade. Foi a primeira quadrilheira a manifestar opinião sobre a publicação na internet, escrevendo o comentário "Lindas imagens”. Algum tempo depois, telefonei para Patrícia para conversar mais acerca do ensaio fotográfico. Ao falar comigo, elogiou as fotografias de Marcus, revelando que se sentiu lisonjeada e grata pelo que denominou como "respeito" que eu dedicava ao trabalho de todos os quadrilheiros de Belém, especialmente às pessoas gays, travestis, transexuais e transgênero. Ao final de nosso contato, revelou sentir saudade de Belém e que estava analisando a possibilidade de retornar à cidade para dançar como dama em sua tão amada Fuzuê Junino. Infelizmente, Patrícia não dançaria naquele São João de 2015. Horas depois de termos nos falado, soube da notícia de que Patrícia havia sido brutalmente assassinada, morrendo aos 27 anos de idade.

De acordo com uma das versões do crime e com as informações dadas por travestis que aparecem nas reportagens sobre o caso, o assassinato de Patrícia fora motivado por disputas por pontos de cafetinagem em Piracicaba. Havia um grupo de travestis que estava aliado a contrabandistas chineses radicados em Piracicaba, que mantinham um pensionato onde abrigavam travestis que se prostituíam. Entretanto, os chineses queriam (com a ajuda das suas aliadas travestis) colocar sob seu domínio, mediante o recebimento regular de propina oriunda de um processo de cafetinagem, outro grupo de travestis que não concordava em ser explorado por suas atividades profissionais no mercado da prostituição. Patrícia Ferraz integrava esse grupo e, justamente por este motivo, foi assassinada a facadas.

A morte de Patrícia causou comoção entre os quadrilheiros e aumentou ainda mais a repercussão do ensaio fotográfico no qual sua foto acabara de ser publicada. Muitos foram os comentários sobre o ensaio, especialmente acerca da fotografia na qual Patrícia é protagonista. A imagem capturou um momento em que Patrícia está radiante de felicidade ao dançar com seu grupo junino. Naquela fotografia, seu sorriso gigantesco parece ter ganhado para si a amplidão de toda a 
quadra junina. Seu traje colorido, cheio de detalhes que sugeriam as cores do arcoíris, dançava ao ritmo de seu corpo. Seu cabelo esvoaçante insistia em também acompanhar os movimentos sugeridos pela música. Suas mãos relaxadas sobre os próprios ombros preparavam-se para serem erguidas ao alto, num momento coreográfico em que seu corpo inteiro crescia em cena através do levantamento de seus braços. Mas eram seus olhos fechados, evidenciando a maquiagem milimetricamente colorida posta sobre suas pálpebras, que revelavam os prováveis sentimentos experimentados por Patrícia naquele instante. Ao fechar os olhos, Patrícia olhava para si e para suas sensações, tentando guardar consigo de maneira mais perene a experiência corporal daquele momento único. Felizmente, Patrícia chegou a ver-se naquela fotografia e, talvez, esta tenha sido uma das últimas alegrias que tenha experimentado. De algum modo, sua relação com as festas juninas de Belém foi eternizada.

O assassinato de Patrícia Ferraz, motivado pelo controle de pontos de prostituição, suscita a ideia de que "essas imagens da brutalidade se relacionam a estéticas sexuais específicas, a determinadas formas subterrâneas de vivenciar a sexualidade. Nelas, quanto maior a intensidade da fruição sexual, maior a propensão à violência” (EFREM FILHO, 2016, p. 330). Quero com isso dizer que, além de uma carga transfóbica, o assassinato contém um desejo de controle sobre corpos e sujeitos considerados abjetos (BUTLER, 2010), cerceando-lhes o direito do exercício autônomo de uma atividade profissional vinculada à fruição da sexualidade. Por um lado, este caso ressalta que a prostituição necessita ser repensada como atividade profissional regulamentada e minimamente fiscalizada pelo Estado como forma de proteção às profissionais que atuam nesse mercado, pauta que a articulação dos movimentos de prostitutas tem colocado em discussão há alguns anos (OLIVAR 2012; 2013). Por outro lado, a morte de Patrícia compõe estatísticas infelizes que colocam em relevo a proeminência numérica do assassinato de sujeitos mais vulneráveis na escala hierárquica do gênero e do comportamento sexual (CARRARA e VIANNA 2004; 2006). Tais sujeitos mais suscetíveis à violência seriam aqueles considerados mais "femininos" como, por exemplo, as mulheres, as travestis, as transexuais e os homossexuais "passivos".

Trouxe aqui a história de Patrícia com o intuito de destacar que o universo quadrilheiro é também circundado por histórias de violência que marcam definitivamente a experiência de vida dos brincantes. Por serem grupos situados nas “periferias" de Belém, portanto, em zonas espaciais estigmatizadas pela presença 
visível do crime, as quadrilhas juninas convivem cotidianamente com a retórica da violência, que atinge, também e obviamente, a diversidade sexual e de gênero que as compõe. De fato, o assassinato de Patrícia nada tem a ver com sua atuação no âmbito junino. Porém, não se trata de um acontecimento isolado, pois inúmeras travestis e transexuais que atuam como brincantes no São João de Belém também desenvolvem atividades profissionais no ramo da prostituição, ainda que, às vezes, essa atuação seja esporádica. Muitas delas me relataram sofrerem ameaças de morte e agressões físicas cotidianamente. $\mathrm{O}$ caso aqui apresentado ilustra um tipo máximo de violência materializado pelo homicídio, mas é interessante notar que todas as travestis e transexuais que integram o conjunto de damas em suas quadrilhas são submetidas, em algum momento de suas trajetórias, a algum tipo de violência simbólica dentro do próprio contexto quadrilheiro. O exemplo mais palpável dessa violência simbólica consiste na dúvida que muitas quadrilhas possuem em relação a aceitar ou não travestis, mulheres transexuais e pessoas transgêneros como membros constituintes de seus respectivos conjuntos de damas. Esse dado etnográfico contraria a falsa impressão de que o contexto das festas juninas seria completamente respeitoso à diversidade sexual e de gênero que nele se faz presente.

\section{Comunidades sexualizadas}

Mas o que nos dizem o linchamento de Dandara dos Santos, a morte de Raíssa Gorbatchof e o assassinato de Patrícia Ferraz? Essas cenas nos falam da vulnerabilidade à qual as pessoas "trans" estão expostas no Brasil com esparsas (e cada vez mais raras) políticas públicas que legitimem o reconhecimento de suas identidades de gênero, que as protejam de crimes de ódio transfóbicos e que tornem, de uma vez por todas, a homo/lesbo/transfobia como crimes tipificados. Esses casos servem para que pensemos nos transfeminismos como expressões necessárias dentro de uma complexa concepção de "feminismos". As identidades "trans" femininas, nesse caso, não se configuram como sujeitos políticos que representam concorrência com as mulheres cisgênero. Pelo contrário, representam uma alteridade "feminina" que se soma às muitas identidades "femininas" já abarcadas pelos feminismos. Sabemos que a categoria "mulher" não é unívoca, como nos apontam Judith Butler, bell hooks, Luiza Bairros, Lélia González, Avtar Brah, Veena Das e tantas outras autoras. 
Nesse sentido, mulheres "trans" nos fazem refletir ainda mais sobre o alargamento da categoria "mulher", compreendendo que se trata de uma experiência social e política mais forte e mais impactante do que os pressupostos biológicos que delimitariam certa universalidade à categoria. Não digo que as demandas sejam as mesmas entre mulheres cis e transgênero, assim como não são as mesmas demandas entre mulheres "brancas" e "negras", nem entre mulheres ricas e pobres, nem entre mulheres hétero e lésbicas. Mas, de todo modo, há conexões potentes entre essas diversas categorias do feminino, pois diferentes níveis de misoginia e transfobia estão sempre à espreita.

Em artigo que publiquei, cujo título é "Comunidades Sexualizadas" (2015), argumento que "a bibliografia feminista tem dado conta de uma ampla crítica aos pressupostos de gênero, raça e classe que figuram como constitutivos da ideia de nação. No entanto, pouca relevância tem sido dada à questão da sexualidade como um fator de peso para a elaboração de uma "comunidade imaginada" em torno da heterossexualidade. Isso denuncia o fato de que há uma opacidade que invisibiliza a heterossexualidade como constitutiva do poder dos Estados-nação" (NOLETO, 2015, p. 132). Dessa maneira, "as comunidades nacionais são também imaginadas em termos sexuais (obviamente heterossexuais) que são postos - e quase sempre invisíveis nas análises - como significantes das nações” (NOLETO, 2015, p. 139). Nesta perspectiva, entendo que "sexualizar uma comunidade nacional é vincular uma ideia de sexualidade à construção de uma imagem pública e simbólica para determinada nação ou grupo social politicamente organizado.

Dessa forma, é possível notar como grande parte das nações - a partir de diversos recursos e dispositivos de representação de si - legitima o expurgo de todo e qualquer componente não heterossexual que possa ser constitutivo de suas imagens e identidades" (NOLETO 2015, p. 137). Assim, tento sublinhar como a homossexualidade (ou outras sexualidades não heterossexuais) é (são) banida(s) através de estupros corretivos (no caso de mulheres lésbicas). No caso de mulheres "trans", o mecanismo utilizado para expurgar essas identidades do tecido nacional são exatamente os assassinatos ou outras modalidades de crimes transfóbicos. Não tenho pretensão de esgotar os exemplos, mas quero dizer que conflitos políticos violentos discutem, explicitamente, uma atribuição de gênero à "comunidade imaginada" e, implicitamente, uma atribuição de sexualidade à identidade nacional. Os transfeminismos são necessários para denunciar a banalidade do mal instaurada entre nós desde há muito tempo. É essa banalidade do mal que, de modo 
implicitamente burocratizado e sistemático, instaura a permissão tácita ao extermínio da população LGBT. Nesse contexto no qual pessoas trans estão expostas a condições de vida que as tornam vulneráveis, os transfeminismos são necessários, principalmente, para nos retirar de um estado de profunda anestesia cultural em que vivemos.

\section{Referências}

ARENDT, Hannah. Eichmann em Jerusalém: um relato sobre a banalidade do mal. São Paulo: Companhia das Letras, 1999 [1963].

BUTLER, Judith. O parentesco é sempre tido como heterossexual? Cadernos Pagu (21): p. 219-260, 2003.

Corpos que pesam: sobre os limites discursivos do "sexo". In: Louro, Guacira (org.) O corpo educado: pedagogias da sexualidade. Belo Horizonte: Autêntica Editora, 2010.

CARRARA, Sérgio; VIANNA, Adriana. As vítimas do desejo: os tribunais cariocas e a homossexualidade nos anos 1980. In: PISCITELLI, A; GREGORI, M. F; CARRARA, S. (org.). Sexualidades e saberes: convenções e fronteiras. Rio de Janeiro: Garamond, 2004. pp. 365-383.

"Tá lá o corpo estendido no chão...": a violência letal contra travestis no município do Rio de Janeiro. Physis 16(2): p. 233-249, 2006.

EFREM FILHO, Roberto. Corpos brutalizados: conflitos e materializações nas mortes de LGBT. Cadernos Pagu 46: 311-340, 2016.

ENKE, Anne Finn. The Education of Little Cis: Cisgender and the Discipline of Opposing Bodies. In: (ed.) Transfeminist perspectives: in and beyond transgender and gender studies. Philadelphia/ Pensilvania: Temple University Press, 2012. p. $60-77$.

FELDMAN, Allen. "On cultural anesthesia: from Desert Storm to Rodney King”. American Ethnologist 21(2): p. 404-418, 1994.

NASCIMENTO, Suely. "Será que ele é?". O Liberal, Caderno Troppo, 10 jun. Belém, p. 16-18, 2001.

NOLETO, Rafael da Silva. "Brilham estrelas de São João!": notas sobre os concursos de "Miss Caipira Gay" e "Miss Caipira Mix" em Belém (PA). Sexualidad, salud y sociedad - Revista latino-americana (18): p. 74-110, 2014.

Comunidades sexualizadas: articulando raça, gênero e sexualidade na construção de nações. In: CANCELA, C. D; MOUTINHO, L; SIMÕES, J (orgs.) Raça, etnicidade, sexualidade e gênero em perspectiva comparada. São Paulo: Terceiro Nome, 2015. p. 121-141. 
Brilham estrelas de São João: gênero, raça e sexualidade em performance nas festas juninas de Belém - PA. Tese de Doutorado, Universidade de São Paulo, 2016a.

"Babados, xotes e xaxados": notas sobre festa, ritual e marcadores sociais da diferença na quadra junina de Belém. Amazônica: Revista de Antropologia 8(1): p. 198-221, 2016b.

. Casamento em performance, parentesco em questão: gênero e sexualidade no São João de Belém, Pará. Cadernos Pagu (51): DOI http://dx.doi.org/10.1590/18094449201700510020, 2017.

NOLETO, Rafael; NEGRÃO, Marcus. Feminilidades coreografadas: gênero, sexualidade e raça nas festas juninas em Belém - Pará. Amazônica - Revista de Antropologia 7(1): 264-277, 2015.

OLIVAR, José Miguel Nieto. Prostituição feminina e direitos sexuais... diálogos possíveis? Sexualidad, salud y sociedade - Revista Latinoamericana, (11): p. 88-121, 2012.

Devir puta: políticas da prostituição de rua na experiência de quatro mulheres militantes. Rio de Janeiro: Eduerj, 2013.

RODOVALHO, Amara Moira. O cis pelo trans. Estudos Feministas 25(1): p. 365373, 2017.

VERGUEIRO, Viviane. Por inflexões decoloniais de corpos e identidades de gênero inconformes: uma análise autoetnográfica da cisgeneridade como normatividade. Dissertação de Mestrado (Cultura e Sociedade). Salvador: Universidade Federal da Bahia, 2015.

\title{
BANALITY OF EVIL, CULTURAL ANESTESIA, SEXUALIZED COMMUNITIES AND TRANS FEMINISMS
}

SOME REFLECTIONS

\begin{abstract}
Articulating the concepts of banality of evil (Hannah Arendt) and Cultural Anesthesia (Allen Feldman), I try to reflect on recent cases involving trans people deaths, either by transphobic violence (Dandara dos Santos - Fortaleza, CE - and Patrícia Ferraz - Belém, PA) or by illness (Raíssa Gorbatchof - Belém, PA). The intention is to reflect on the importance of transfeminismos in combating the vulnerability to which transvestite and transsexual population is subjected daily. I intend to reflect on how the forms of extermination of these subjects seek to rebuild nations as sexualized communities, based (obviously) on the hegemony of heterosexuality and cisgenerity.
\end{abstract}

Keywords: Transsexuality; Transfeminisms; Violence. 
Recebido: 22/05/2018.

Aceito: 07/06/2018. 